\title{
Zoonosis: Update on Existing and Emerging Vector-Borne Illnesses in the USA
}

\author{
Sandra Lee Werner ${ }^{1} \cdot$ Bhanu Kirthi Banda ${ }^{1} \cdot$ Christopher Lee Burnsides $^{1} \cdot$ Alexander James Stuber ${ }^{1}$ \\ Published online: 13 August 2019 \\ (C) Springer Science+Business Media, LLC, part of Springer Nature 2019
}

\begin{abstract}
Purpose of review This review describes mosquito- and tick-borne diseases found in the Western Hemisphere. It focuses on emerging diseases and recent geographic shifts in the presence of disease vectors.

Recent Findings Mosquito and tick vectors have become more widespread as environmental conditions have become more favorable. Zika recently has emerged as a concern for fetal anomalies. West Nile Virus has become widespread. Lyme disease and other tick-borne diseases are more prevalent in areas previously inhospitable to these ticks.

Summary Healthcare providers must consider the possibility of mosquito- and tick-borne diseases in broader geographic areas and council patients traveling to endemic areas on precautions against these diseases. Treatment for suspected cases of serious tick-borne illnesses should not be delayed pending culture results.
\end{abstract}

Keywords Zoonosis · Tick · Mosquito · Zika - Lyme · Vector-borne

\section{Introduction}

Vectors are organisms that spread diseases between humans and from animals to humans. Diseases transmitted may be bacterial, viral, or parasitic. Worldwide, 1.7 million people are affected annually by vector-borne illnesses [1]. In the USA, ticks and mosquitos are the primary disease vectors, with tick-borne illnesses accounting for $75 \%$ of cases [2••]. The incidence of vector-borne illnesses in the USA increased threefold between 2004 and 2016 and nine new vector-borne

This article is part of the Topical Collection on Infectious Disease

Sandra Lee Werner

swerner@metrohealth.org

Bhanu Kirthi Banda

Bbanda1@metrohealth.org

Christopher Lee Burnsides

Cburnsides1@metrohealth.org

Alexander James Stuber

astuber@metrohealth.org

1 MetroHealth/Cleveland Clinic/CWRU Emergency Medicine

Residency Program, Department of Emergency Medicine,

MetroHealth Medical Center, 2500 MetroHealth Drive,

Cleveland, OH 44109, USA diseases were reported in the USA and its territories [2••]. The geographic range of many tick and mosquito vectors has also increased, a trend that will likely continue in conjunction with a rise in average temperatures.

The increasing prevalence of these diseases is concerning as there are very few vaccines against vector-borne diseases and no specific treatment for many of the vector-borne illnesses. In addition, for some tick-borne illnesses, early antibiotics are lifesaving. It is critical that healthcare providers consider vectorborne illnesses in the differential for patients with rash and/or febrile illnesses and any potential vector exposure, including travel within and outside the USA. Healthcare providers must also actively instruct patients in the awareness and prevention of vector-borne diseases. Table 1 provides a summary of prevention strategies for tick- and mosquito-borne diseases.

In the USA, the predominant tick-borne diseases are Lyme, spotted fever rickettsiosis (including Rocky Mountain spotted fever), ehrlichiosis, anaplasmosis, tularemia, and babesiosis [3]. Emerging diseases include Powassan, Heartland, and Bourbon viruses $[2 \bullet \bullet$. The most widespread mosquito-borne illnesses are West Nile Virus (WNV) and Zika; chikungunya and dengue have also been recently reported in the USA [2••].

This article provides updates in the epidemiology, clinical presentations, current diagnostic methods, and recommended treatment for the major and emerging tick- and mosquitoborne illnesses present in the USA. 
Table 1 Vector-borne disease prevention strategies

\begin{tabular}{|c|c|c|}
\hline Strategy & Ticks & Mosquitos \\
\hline $\begin{array}{l}\text { EPA-approved } \\
\text { repellants }\end{array}$ & $\begin{array}{l}\text { DEET } \\
\text { Picaridin } \\
\text { IR3535 } \\
\text { Oil of lemon eucalyptus (OLE) } \\
\text { Para-menthane-diol (PMD) } \\
\text { 2-Undecanone }\end{array}$ & $\begin{array}{l}\text { DEET } \\
\text { Picaridin } \\
\text { IR3535 } \\
\text { Oil of lemon eucalyptus } \\
\quad \text { (OLE) } \\
\text { Para-menthane-diol } \\
\quad \text { (PMD) } \\
\text { 2-Undecanone }\end{array}$ \\
\hline \multirow[t]{2}{*}{ Clothing } & $\begin{array}{l}\text { Wear long-sleeved shirts and } \\
\text { pants, socks, and shoes } \\
\text { Tuck socks into shoes }\end{array}$ & $\begin{array}{l}\text { Wear long-sleeved shirts } \\
\text { and pants, socks, and } \\
\text { shoes }\end{array}$ \\
\hline & $\begin{array}{l}\text { Wear permethrin-treated } \\
\text { clothing }\end{array}$ & $\begin{array}{l}\text { Wear permethrin-treated } \\
\text { clothing }\end{array}$ \\
\hline \multirow[t]{4}{*}{ Environment } & $\begin{array}{l}\text { Expect ticks in woodland, } \\
\text { brushy, or grassy areas }\end{array}$ & $\begin{array}{l}\text { Empty containers of } \\
\text { standing water at least } \\
\text { weekly }\end{array}$ \\
\hline & Inspect clothes, gear, and pets & $\begin{array}{l}\text { Use mosquito larvicide in } \\
\text { ponds and other water } \\
\text { features }\end{array}$ \\
\hline & $\begin{array}{l}\text { Conduct a full body scan for } \\
\text { ticks, especially in the hair, in } \\
\text { and behind the ears, the axilla, } \\
\text { navel, waistline, perineum, and } \\
\text { popliteal fossa }\end{array}$ & \\
\hline & Shower after potential exposure & \\
\hline \multirow[t]{2}{*}{ Dwellings } & Avoid rodent-infested cabins & $\begin{array}{l}\text { Use window and door } \\
\text { screens }\end{array}$ \\
\hline & $\begin{array}{l}\text { Inspect pets coming into the } \\
\text { house }\end{array}$ & $\begin{array}{l}\text { Repair holes in screens } \\
\text { Use air conditioning when } \\
\text { possible }\end{array}$ \\
\hline Vector removal & $\begin{array}{l}\text { Grasp the tick as close to the } \\
\text { skin as possible with tweezers } \\
\text { and pull straight out with steady } \\
\text { pressure. Do not twist or jerk. } \\
\text { Clean the area with soap and } \\
\text { water or rubbing alcohol }\end{array}$ & N/A \\
\hline $\begin{array}{l}\text { Novel } \\
\quad \text { interventions }\end{array}$ & & $\begin{array}{l}\text { Bacterial infection of } \\
\text { mosquitos to prevent } \text { propagation }^{\mathrm{a}}\end{array}$ \\
\hline
\end{tabular}

${ }^{\text {a }}$ O'Neill, SL, Ryan PA, Turley AP, Wilson G. et al. Scaled deployment of Wolbachia to protect the community from Aedes transmitted arboviruses. Gates Open Research 2018. Available at http://www.eliminatedengue. com/library/publication/document/publications/scott oneill 082018.pdf. Updated August 1, 2018. Accessed May 22, 2019. THIS ARTICLE IS STILL AWAITING PEER REVIEW.

\section{Tick-Borne Diseases}

There are nine tick species found in the USA, several of which commonly bite humans: the black-legged tick (Ixodes scapularis), the dog tick (Dermacentor variabilis), the lone star tick (Amblyomma americanum), and the soft tick (Ornithodoros spp.). The black-legged tick is found throughout the eastern USA and is responsible for the transmission of Lyme disease, anaplasmosis, babesiosis, ehrlichiosis, and Powassan fever, as well as a form of relapsing fever. The dog tick is widely distributed east of the Rocky Mountains and in isolated areas on the Pacific Coast. This tick transmits Rocky Mountain spotted fever and tularemia.

The lone star tick was originally found only in the southeast but is now widely distributed in the entire eastern USA and transmits ehrlichiosis, tularemia, and southern tick-associated rash illness (STARI). In addition, bites from this tick have been associated with the development of an allergy to galactose- $\alpha-1,3-$ galactose ( $\alpha$-gal), a type of sugar found in beef, pork, lamb, and other red meats [4]. Soft ticks are found throughout the western states including Texas. They transmit tick-borne relapsing fever. A discussion of the epidemiology, clinical presentation, diagnosis, and treatment of each of the major diseases is presented in the following sections. Table 2 provides a guide to the tick-borne diseases covered, including their associated vectors, current geographic range, signs and symptoms, and treatment.

\section{Lyme Disease}

\section{Epidemiology}

Lyme disease is the most common vector-borne illness in North America, with more than 300,000 cases reported annually and an upward trend [5]. It is caused by the spirochete Borrelia burgdorferi. Disease prevalence follows a geographic pattern based on the distribution of its primary vector, the Ixodes tick, and its mammalian life cycle hosts, the white-tailed deer and white-footed mouse [6]. Recent studies have concluded that climate change may have sizeable effects on its epidemiology [7••, 8]. A 2018 study employed fixed effects analysis to examine the impact of climatic variables such as temperature and precipitation in 15 North American states with the highest incidence of Lyme disease. These results were used to project a greater than $20 \%$ increase in Lyme disease cases in the USA, assuming a midcentury $2{ }^{\circ} \mathrm{C}$ increase in temperature as predicted by the U.S. National Climate Assessment [8].

\section{Clinical Presentation}

Lyme infection typically progresses through three discrete stages: early localized, early disseminated, and late disease. Early localized disease manifests as erythema chronicum migrans otherwise known as a "bull's eye rash" due to the characteristic central clearing; however, this lesion may appear uniformly erythematous (see Fig. 1). If left untreated, this is followed by early disseminated disease, which typically causes inflammation of the heart and nervous systems. The most common cardiac presentation is an AV nodal heart block, although peri- and myocarditis may also occur [9]. The most common neurologic presentations are nerve palsies and meningitis [9]. Late disease, which occurs months to years after a tick bite, most commonly presents as mono- or polyarticular arthritis. Rarer manifestations of late 


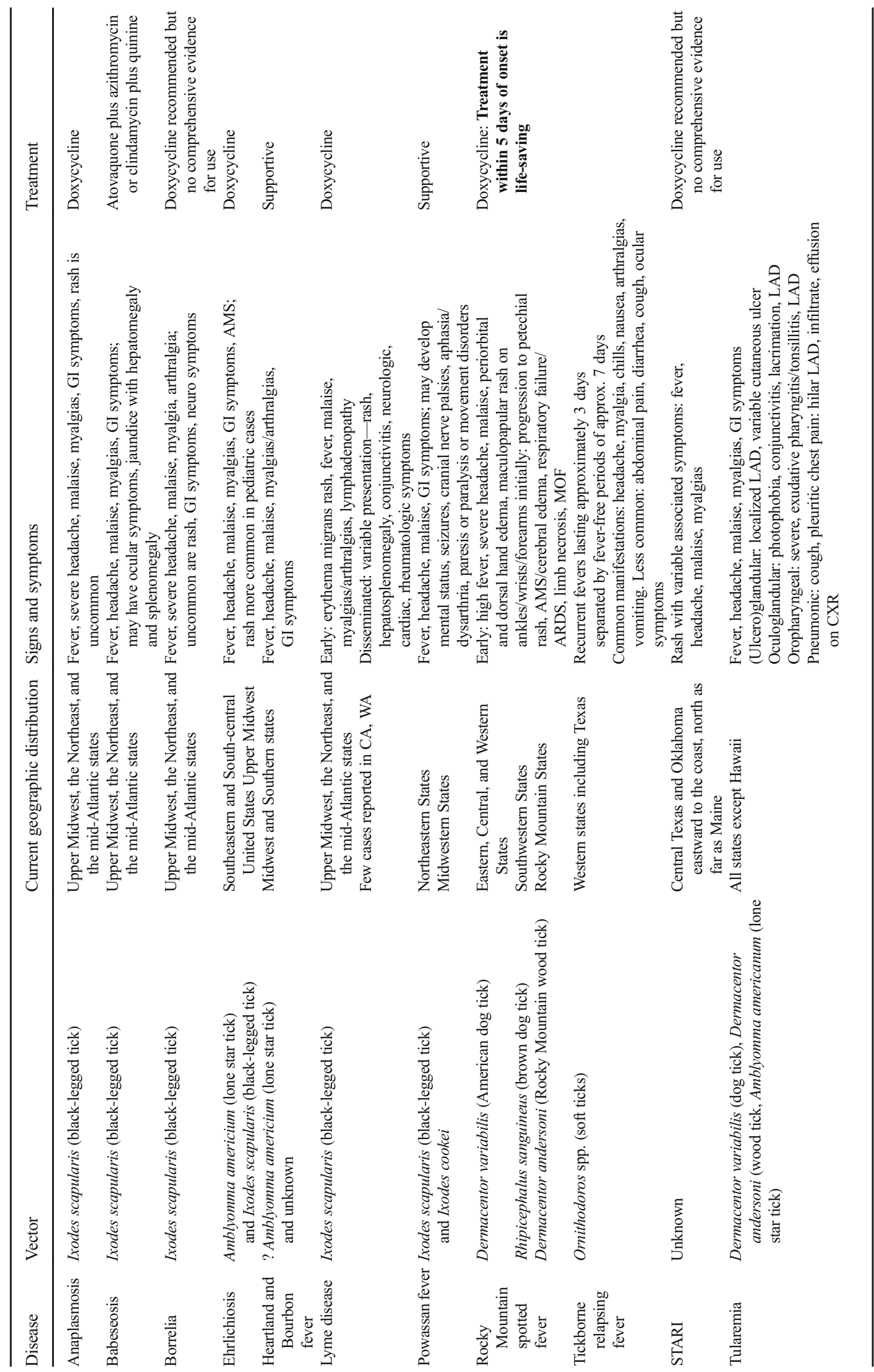




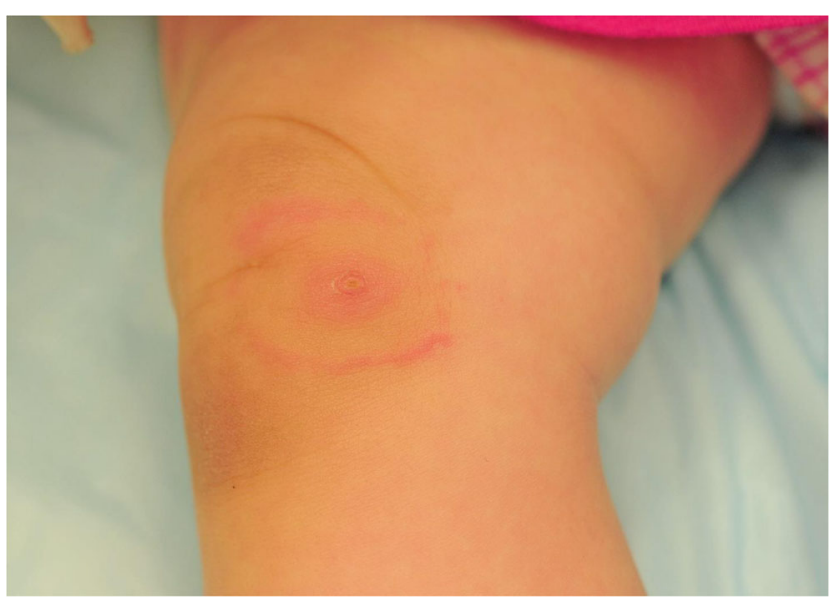

Fig. 1 Courtesy of David Effron, MD

disease comprise a variety of neurologic symptoms such as memory loss, pain, and paresthesias [5, 6, 9].

\section{Diagnosis and Treatment}

Current CDC guidelines call for two-tiered laboratory testing for accurate diagnosis [10]. Initially, an enzyme immunoassay or immunofluorescence assay is performed. If either yields a positive or equivocal result, immunoblot is performed as confirmation. However, this method may have poor sensitivity in cases of localized and early infections. It is important to remember that patients can remain immunoblot positive from past infections [11]. A 2015 systematic review and metaanalysis was unable to find evidence proving superiority of a two-tiered approach when compared to single tests $[11,12]$.

Treatment options for early localized disease include doxycycline, amoxicillin, or cefuroxime. Doxycycline (100 mg twice daily for 10-21 days) is recommended for most patients based on its efficacy against co-infections transmitted through Ixodes subspecies such as anaplasmosis [9]. Amoxicillin, $50 \mathrm{mg} / \mathrm{kg}$ daily divided into three daily doses, is recommended as first-line treatment in pediatric patients with early disease. For early disseminated disease presenting with Bell's palsy, oral doxycycline is recommended. For other neurologic manifestations such as meningitis, symptomatic carditis, or AV block, patients should be admitted to hospital for monitoring and IV antibiotics [9]. Two to 3 weeks of an IV cephalosporin with cerebrospinal fluid (CSF) penetration is recommended for meningitis [9]. Late Lyme disease is typically treated with IV ceftriaxone, cefotaxime, or penicillin $G$ for 28 days.

\section{Babesiosis}

\section{Epidemiology}

Babesiosis is a parasitic, tick-borne infection of the red blood cells, primarily caused by Babesia microti in North America.
Transmission tends to occur in the spring and summer months in the Northeast and Upper Midwest. The primary vector is the Ixodes tick, which is also responsible for spread of Lyme disease and anaplasmosis [13]. This makes the possibility of co-infection a critical consideration, particularly for Lyme disease, because doxycycline is ineffective for treatment of babesiosis [14•]. It is important to note that while concurrent infection with Lyme disease can increase the severity of the acute illness, complications arising from chronic Lyme disease are not affected by co-infection with babesiosis [14 $\bullet$, 15]. There has also been a recent recognition of transfusiontransmission in the USA by the American Association of Blood Banks, which launched a risk-based decision-making assessment of "Babesia donation testing" intervention. As a result, RNA-based nucleic acid test assays are currently being employed in endemic areas with a goal of further expansion [16].

\section{Clinical Presentation}

Babesiosis has a varied clinical presentation, ranging from a complete lack of symptoms to multi-organ failure; this is often dependent on the patient's immunocompetence, with severe disease more often in asplenic patients [13, 17]. Although most cases of babesiosis in otherwise healthy individuals have a benign course, healthcare providers should be aware of risk of progression to fulminant disease. Multiple recent case studies have demonstrated significant morbidity and mortality from ARDS, hemolysis and thrombocytopenia, hypotension, and nosocomial infections $[18,19]$. Splenic rupture is another severe complication of babesiosis, with a higher incidence in younger, healthy patients with a lower degree of parasitemia, possibly due to a strong immunologic splenic response to infection [20].

\section{Diagnosis and Treatment}

Diagnosis of babesiosis is typically done by a peripheral thin blood smear along with PCR testing. Serology can be used to confirm infection. However, a single positive test cannot distinguish between acute and previous undiagnosed infections. A 2018 retrospective study found a false negative peripheral smear in more than $25 \%$ of infections, demonstrating the importance of patient history and other clinical indicators in these patients [21]. Treatment of choice is atovaquone and azithromycin for 7 to 10 days [17]. Another option is quinine and clindamycin; this regimen is associated with a higher rate of adverse reactions but is required for severe disease requiring hospitalization and for immunocompromised patients [17]. Exchange transfusion is reserved for severe cases of hemolysis. 


\section{Rocky Mountain Spotted Fever}

\section{Epidemiology}

Rocky Mountain spotted fever (RMSF) is a bacterial tick-borne infection caused by Rickettsia rickettsii, which is responsible for the most severe and fatal outcomes of all the spotted fever group rickettsioses $[22,23]$. Due to the inability to accurately and rapidly differentiate between RMSF and its typically less serious mimics (Pacific coast fever, Rickettsia parkeri rickettsiosis, and rickettsial pox) early in its course, RMSF cases are reported by the CDC under a broad category of spotted fever rickettsiosis (SFRs) as of 2010 [24]. The majority of RMSF cases in the USA occur in the following five states: North Carolina, Oklahoma, Arkansas, Tennessee, and Missouri. Certain areas of Arizona have recently hosted an increasing number of cases with case fatality of $10 \%$ [22].

\section{Clinical Presentation}

Signs and symptoms of RMSF typically appear 3 to 12 days after the initial tick bite with the incubation period being inversely proportional to severity of disease [23]. Patients can present with a range of non-specific symptoms including fever, chills, headache, and fatigue. The trademark petechial rash on the palms and soles that often leads to diagnosis does not appear until the fifth or sixth day of infection. If left undiagnosed, the disease progresses to renal failure, meningoencephalitis, acute respiratory distress syndrome, and shock and may result in death in more than $20 \%$ of untreated cases $[22,23]$.

\section{Diagnosis and Treatment}

There is no widely available rapid confirmatory testing for SFRs in acutely infected patients so RMSF should always remain in the differential in patients with fever of unknown origin in the spring and summer months, with an elevated suspicion in patients who may have been exposed to ticks or those who reside in lower midwestern/southeastern states [25]. The current gold standard diagnostic method is via indirect immunofluorescence antibody assay, which should always be performed using paired serum samples from acute and convalescent phases. It is important to note that single or inappropriately timed samples are easily misinterpreted and should be avoided. Polymerase chain reaction (PCR) is a highly specific test; early stages of infection often test negative and treatment should not be withheld in clinically suspicious patients with negative PCR testing [26].

Antibiotics are administered based on clinical suspicion alone. Treatment should not be delayed until the appearance of a rash or other characteristic symptom in cases with a high clinical suspicion for RMSF. While the incidence of SFR continues to rise, mortality and morbidity have decreased since the mid-1900s due to the availability of tetracyclines and a recent push for early antibiotics in suspected cases [22, 27]. The leading predictor of fatality in RSMF is a delay in antibiotics. Doxycycline is the preferred antibiotic for all ages and regardless of pregnancy status [28]. For adults and children weighing over $45 \mathrm{~kg}, 100 \mathrm{mg}$ should be administered twice daily either intravenously or orally. For children under $45 \mathrm{~kg}$, the recommended doxycycline dose is $2.2 \mathrm{mg} / \mathrm{kg} /$ dose twice daily. Treatment should be continued for at least 3 days following resolution of fever, which can range from $42 \mathrm{~h}$ to 5 days depending on the severity of illness [29]. Doxycycline has been shown to prevent severe morbidity and mortality if given within 5 days of symptom onset $[22,29]$. Despite this recommendation, as recently as 2014, only $35 \%$ of healthcare providers were willing to use doxycycline in suspected pediatric RMSF cases due to occurrences of dental staining caused by older generations of tetracyclines [30 $[$. However, studies by the CDC and Indian Health Services failed to show any dental discoloration or enamel hypoplasia in children under 8 years of age who received short-term courses of doxycycline [31, 32].

\section{Ehrlichiosis}

\section{Epidemiology}

Ehrlichiae are obligate intracellular rickettsia that replicate in human and animal leukocytes. The predominant strains implicated in causing ehrlichiosis are Ehrlichia chaffeensis, Ehrlichia ewingii, and Ehrlichia muris eauclairensis [33, 34]. The lone star tick (A. americanum) has been directly linked to $80-90 \%$ of cases of ehrlichiosis, with the remainder of cases associated with the black-legged tick, which carries E. muris eauclairensis in the Wisconsin/Minnesota area [33, 34]. Only E. chaffeensis has been associated with fatal illnesses [35]. The incidence of ehrlichiosis in the USA has increased fourfold since 2000 [35]. Most cases occur in the spring and summer months throughout the south-central and eastern USA [33, 34]. Even with improved reporting of cases, serologic studies suggest the incidence of unreported and likely asymptomatic cases is significant [33].

\section{Clinical Presentation}

Ehrlichiosis typically presents as an acute illness but, less commonly, has a more prolonged subacute course. Symptoms typically follow an incubation period of 5-14 days and consist of flulike symptoms: fevers, malaise, myalgias, headache, vomiting (25-50\%), cough (25-50\%), and less commonly rash (36\%) [33]. Altered mental status may be seen in more severe cases [35]. Of note, in rare transfusion acquired cases, the donors were noted to be asymptomatic [33]. There has been one case report of rapidly progressive myocarditis attributed to ehrlichiosis [33]. The elderly and immunocompromised tend to have a more severe course of illness $[33,35]$. 


\section{Diagnosis and Treatment}

Laboratory workup is non-specific. Leukopenia, thrombocytopenia, transaminitis, and elevated $\mathrm{LDH}$ and alkaline phosphatase are seen in $50-90 \%$ of cases [33]. Definitive diagnosis can be accomplished through rapid PCR DNA testing. This test is most sensitive during the first week [35]. Alternative testing is through the demonstration of a fourfold rise in Ig-G using paired samples drawn during the first week of illness and 2-4 weeks later [35].

Treatment of ehrlichiosis should not be delayed for confirmatory testing. First-line treatment for all patients, including children and pregnant women, is doxycycline, IV or PO, depending on disease severity [35]. Treatment should continue for 3 days after fever subsidence and for a minimum of 5-7 days. Rifampin is recommended as a second-line agent for those with severe allergies, and chloramphenicol is a distant third choice [33]. There is no vaccine against ehrlichiosis.

\section{Anaplasmosis}

\section{Epidemiology}

Anaplasmosis is caused by the bacterium Anaplasma phagocytophilum. Anaplasmosis was formerly known as human granulocytic ehrlichiosis (HGE), and A. phagocytophilum was Ehrlichia phagocytophilum [36]. The disease is transmitted primarily through the bite of the black-legged tick (I. scapularis) and the western black-legged tick [37]. The black-legged tick is found throughout the eastern USA from Texas to North Dakota and the western black-legged tick is found along the west coast from Southern California to Washington State with extension as far east as Utah [37]. Most cases occur during the summer and late fall seasons with peaks in June/July and October/November. The number of reported cases has increased from 348 in 2000 to 5762 in 2017, and the number of states with cases has increased, corresponding to the increased range of the black-legged tick [38]. In 2017, 90\% of reported cases occurred in eight states (Vermont, Maine, Rhode Island, Minnesota, Massachusetts, Wisconsin, New Hampshire, and New York) [38]. In addition to transmission by infected ticks, anaplasmosis has been transmitted through blood and organ transfusion [37].

\section{Clinical Presentation}

The incubation period for anaplasmosis is 5-14 days. However, patients may not provide a history of a tick bite as the bite is usually painless and the tiny nymphal ticks feeding during the summer months may not be detected. Early anaplasmosis presents as an acute febrile illness. Common symptoms include fever, chills, malaise, myalgias, and less commonly vomiting and diarrhea $(20 \%)$ [37, 39]. A rash is present in about $10 \%$ of cases and may present co-infection with Lyme disease [39]. Even more rarely reported is CNS involvement with meningitis, paralysis, and encephalitis [39]. Serious disease is rare, but untreated or late stage disease may result in renal or respiratory failure, peripheral neuropathies, disseminated intravascular coagulation (DIC)-like coagulopathies, rhabdomyolysis, and hemorrhage $[37,38]$. As with many diseases, more serious complications occur more often in the elderly, pregnant, and immunocompromised patients.

\section{Diagnosis and Treatment}

Basic laboratory evaluation may reveal anemia, leukopenia with lymphopenia and a left shift, thrombocytopenia, and a mild transaminitis [37, 39]. Definitive testing for anaplasmosis may be accomplished with the detection of DNA by PCR. This test is most sensitive in the first week of illness. A negative test does not rule out the diagnosis [39]. The definitive diagnosis is completed with serologic immunofluorescence antibody (IFA) testing for IgG completed 2-4 weeks apart. Positive testing is determined by a fourfold increase from initial testing to the repeat at 2 4 weeks. IFA testing is poorly sensitive in the first week of illness and should be repeated if negative and a high suspicion remains for anaplasmosis [38].

Treatment of suspected anaplasmosis should not be delayed pending DNA or culture results. Doxycycline remains the treatment of choice for anaplasmosis in patients of all ages and regardless of pregnancy status [34, 36, 38, 39]. The dose is $100 \mathrm{mg}$ twice daily for adults and $2.2 \mathrm{mg} / \mathrm{kg}$ daily in two doses for pediatric patients either IV or PO depending on the severity of illness. Recommended course of treatment is 10-14 days [38]. For patients with serious allergies to doxycycline, rifampin has been documented as an alternative [37].

\section{Tick-Borne Relapsing Fever}

\section{Epidemiology}

In North America, tick-borne relapsing fever (TBRF) is caused by two related spirochetes, Borrelia turicatae in the nonmountainous regions of the southwest and Borrelia hermsii (most common) in the Mountainous regions of the western USA [40]. Most cases are transmitted through the bite of Ornithodoros spp. (soft ticks) [40]. A total of 504 cases of TBRF were reported between 1990 and 2011. Most cases occurred in 14 western states: Arizona, California, Colorado, Idaho, Kansas, Montana, Nevada, New Mexico, Oklahoma, Oregon, Texas, Utah, Washington, and Wyoming [41]. More recent data is not available. However, there was outbreak of TBRF in Arizona in 2014 with 11 cases [42, 43]. It is likely that total cases are under-reported as mild cases may not be reported and there is no standard surveillance case definition in the 12 states where reporting is required [41].

Soft ticks generally live in rodent-infested houses or caves. Rodents, including chipmunks and squirrels, are the usual 
reservoir for the disease [41]. These ticks are remarkably hardy, with a lifespan of 20 years and the ability to survive without a blood meal for several years [40]. The risk of acquiring relapsing fever after a bite is approximately 50\% [40]. Due to the short feeding period (less than $30 \mathrm{~min}$ ), the majority of people are unaware they were bitten [44].

\section{Clinical Presentation}

The onset of TBRF follows an incubation period of 3-12 days. The syndrome begins with a sudden onset of high fever and progresses to a "crisis" phase [44, 45]. The crisis manifests as rigors, tachycardia, and hypertension, soon followed by defervescence with associated diaphoresis and hypotension. The crisis may last several hours. After the initial febrile episode, there are recurrent febrile periods lasting 1-3 days, with 4-14 feverfree days in between $[44,45]$. In addition to fevers, a wide breadth of symptoms may occur due to the spread of spirochetes throughout the organ systems: neurologic: encephalopathy, myelitis, and meningitis; cardiopulmonary: myocarditis; pulmonary: ARDS; hematologic: thrombocytopenia and coagulopathy [45]. As with many diseases, pregnant, elderly, and immunocompromised often have a more severe and prolonged course.

\section{Diagnosis and Treatment}

Laboratory workup may reveal thrombocytopenia, elevated erythrocyte sedimentation rate (ESR), elevated bilirubin, and slightly elevated thrombin and prothrombin times. If CSF studies are performed, a mononuclear pleocytosis and elevated protein level are usually seen [45]. Definitive diagnosis is made through manual peripheral blood smear analysis during the febrile stage of illness when spirochetes are found in the bloodstream [45]. PCR can be performed if initial smears are negative, but suspicion is high. PCR may be performed on blood, CSF samples, or other culture medium [45]. Cultures are possible but limited as few labs have the capability to perform the studies [45].

TBRF is treated with tetracycline or erythromycin $500 \mathrm{mg}$, four times daily for 10 days with the exception of CNS disease which requires $2 \mathrm{G}$ IV ceftriaxone daily for 10-14 days. Children weighing less than $100 \mathrm{~kg}$ may be treated with erythromycin, $12.5 \mathrm{mg} / \mathrm{kg}$ daily. During the initial few hours, treatment of TBRF patients must be monitored for Jarisch-Herxheimer reaction as this has been found to occur in 54\% of cases [45].

\section{Southern Tick-Associated Rash IIIness}

\section{Epidemiology}

Southern Tick-Associated Rash Illness (STARI) is an enigma. The STARI syndrome has been described in the southern states of Mississippi, Missouri, Maryland, Georgia, and the Carolinas with one case on Long Island [46, 47]. It was postulated that the syndrome is caused by transmission of Borrelia lonestari through the bite of the lone star tick (A. americanum) given the presence of this tick in these southern states. However, the bacteria have not been isolated from a human with STARI. Even positive PCR testing has been limited to one case [46]. In addition, testing of 31 patients with presumed STARI in Missouri failed to yield evidence of infection by $B$. lonestari so the cause of STARI remains unknown [48]. As with many ticks, the lone star tick's range has expanded, with the ticks found as far west as central Texas and as far North as Maine [49]. It will be interesting to see if the range of STARI cases expands as well.

\section{Clinical Presentation}

STARI is a clinical syndrome based on the presence of an erythema migrans-like rash following a history of tick bite in an area where Lyme disease is uncommon or unknown or where Lyme testing is negative. The EM-type rash is associated with a flu-like illness of headache, myalgias, malaise, and/or nausea. In comparison to patients with Lyme disease, patients with STARI were more likely to recall a tick bite, have a shorter onset of skin lesion (6 days on average), less likely to have other symptoms, less likely to have multiple skin lesions, and to improve more rapidly following antibiotic treatment $[46,47]$.

\section{Diagnosis and Treatment}

There is no laboratory test to confirm the diagnosis of STARI. However, in patients with STARI, laboratory testing for Lyme is negative. Case series have demonstrated successful treatment with doxycycline or amoxicillin for patients allergic to doxycycline [46]. However, the actual necessity and duration of antibiotic treatment are not clear.

\section{Tularemia}

\section{Epidemiology}

Tularemia is a relatively well-known zoonotic infection caused by Francisella tularemia, an aerobic, gram-negative bacterium. In the past, most cases occurred in the summer months and originated in south-central states [50]. However, the disease is now widespread with cases reported in all states except Hawaii. The increase in cases in the North-central region of the country is suspected to be related to warmer temperatures in this area $[51,52 \cdot]$.

Tularemia is transmitted through multiple routes. Most commonly, it is spread through insect bites, usually ticks and deer flies. The most common tick vectors are the dog tick, the wood tick, and the lone star tick [50]. Rarely, the disease is caused by the bite of infected animals or through ingestion of contaminated food/water from infected animal tissue [50]. It can also be transmitted through skin contact with an infected 
animal tissue. Airborne transmission was documented in the 2000 Martha's Vineyard tularemia outbreak [53]. Of note, the ability of $F$. tularemia to be aerosolized has led to concern of it being used as a bioterrorism agent [54].

\section{Clinical Presentation}

The clinical presentation of tularemia varies depending on several factors, including the route of inoculation [55]. The usual incubation period is 3-5 days, with a range of 1-21 days [55]. Tularemia typically presents with an abrupt onset of nonspecific flu-like symptoms including fever, headache, sore throat, cough, myalgias, abdominal pain, nausea/vomiting, and diarrhea. The ulceroglandular form presents with localized lymphadenopathy and, variably, a cutaneous ulcer at the inoculation site. The oculoglandular form features photophobia, conjunctivitis, lacrimation, and pre-auricular or cervical lymphadenopathy. Oropharyngeal cases present with severe throat pain, exudative pharyngitis, and cervical, pre-parotid, and/or retropharyngeal adenopathy. The pneumonic form presents with pleuritic chest pain, cough, and findings of hilar adenopathy, infiltrate, and/or effusion on CXR. The typhoid form is characterized by any combination of the generalized symptoms without the localizing symptoms of the other forms.

\section{Diagnosis and Treatment}

General laboratory studies are non-diagnostic and may reveal leukocytosis, thrombocytopenia, elevated ESR, hyponatremia, elevated transaminases, elevated $\mathrm{CK}$, myoglobinemia, and sterile pyuria. Definitive diagnosis is made through the isolation of F. tularemia in a clinical specimen or detection of tularemia in a specimen by PCR or DFA. Additionally, the diagnosis may be made through a demonstrated fourfold increase in F. tularemia titers drawn at presentation and again 2-4 weeks later or a single positive antibody titer in a clinical specimen to the tularensis antigen [55].

Treatment consists of aminoglycoside (gentamicin or streptomycin) IV or IM for a minimum of 10 days for severe disease. Doxycycline or ciprofloxacin may be used for mild/moderate disease, although new evidence demonstrates increased resistance to fluoroquinolones [55]. Post-exposure prophylaxis is limited to only bioterrorism events and confirmed or highly suspected exposure events in high-risk individuals (lab workers, autopsy workers, exposure to cases with non-intact skin).

There is no tularemia vaccine as the previously offered live vaccine is no longer available. A vaccine developed by the US army underwent a phase 2 trial showing similar safety and superior antibody responses compared to the older USAMRIID vaccine but is not yet available [55].

\section{Powassan Disease}

\section{Epidemiology}

Powassan virus is a neurovirulent flavivirus which causes meningio-encephalititis [56••]. Infections are rare but increasing in number. From 1958 to 1998, there were 27 cases, and from 1999 to 2016, there were 98, representing an increase of $671 \%$ over the last 18 years [56••]. Cases have been reported in the Northeast and Great Lakes region [57]. Powassan infection is transmitted primarily by the black-legged tick (I. scapularis) in the East and Ixodes cookei in the Midwest and Canada [56••].

\section{Clinical Presentation}

The incubation period is $1-4$ weeks. Presenting symptoms include fever, headache, vomiting, and generalized weakness. However, the disease can progress to encephalitis, meningoencephalitis, or aseptic meningitis. Patients with encephalitis may develop altered mental status, seizures, cranial nerve palsies, aphasia/dysarthria, paresis or paralysis, or movement disorders [56••]. Powassan disease should be considered in the differential along with herpes, enteroviruses, and other arboviruses for patients with fever and neurologic symptoms [57]. The case fatality rate is about $10 \%$ and $50 \%$ of survivors have long-term neurologic symptoms [57].

\section{Diagnosis and Treatment}

CSF findings usually include lymphocytic pleocytosis. However, neutrophils can predominate early in the disease. CSF protein is usually normal or slightly elevated, and glucose is normal. Definitive diagnosis can be made through ELISA-based IgM and IFA assay [58]. Electroencephalography (EEG) may be conducted and show generalized slow wave activity (similar pattern seen in herpes simplex virus encephalitis) [57]. Magnetic resonance imaging (MRI) of the brain may reveal hyperintensities in both superficial and deep white matter [57].

There is no specific treatment for Powassan virus. There is no vaccine. Severe cases require hospitalization. Supportive measures include IV fluids, ventilatory support, and treatment for increased ICP.

\section{Heartland and Bourbon Viruses}

\section{Epidemiology}

More than 40 cases of Heartland virus and several cases of Bourbon virus have been reported in midwestern and southern states as of 2018 [59•, 60•]. These viruses were unknown in the USA prior to approximately 2010. The Heartland virus is one of the Phleboviridae, known to be transmitted by several 
insect vectors [59•]. Bourbon virus belongs to a group of viruses called thogotoviruses which are widespread worldwide [60•]. Heartland virus is thought to be spread by the lone star tick but may be carried by others as well [61]. Bourbon virus is suspected to be transmitted by ticks but which species is unknown.

\section{Clinical Presentation}

Both diseases present with symptoms typical of tick-borne illnesses: high fever, malaise, headache, nausea and vomiting, and myalgias. A maculopapular rash has also been described in cases of Bourbon fever. Most victims recall a tick bite within 2 weeks of the onset of disease. Most patients recover but there have been several case fatalities from both of these viruses [62, 63].

\section{Diagnosis and Treatment}

Routine laboratory testing may reveal leukopenia and thrombocytopenia [59•, 60•]. Most institutions do not have the capability to test for these viruses, but state health departments have protocols for diagnosing both these viruses. Healthcare providers with suspected cases should notify their state health department. Treatment is supportive with IV fluids, pain medications, antipyretics, and antiemetics.

\section{Mosquito-Borne Diseases}

There are two types of mosquito-borne disease transmission: anthroponotic, meaning humans are the primary vertebrate host, and zoonotic, where there is at least one animal host and humans are a secondary host.

Anthroponotic mosquito-borne illnesses, including malaria and yellow fever, were once common in the USA but efforts to eradicate mosquitos as well as improved sanitation and changes in social lifestyles led to near complete disappearance of these diseases by 1962 [64••]. However, one of the mosquito vectors, the Aedes aegypti, was not completely eradicated and has re-established its presence in large areas of the USA. Mathematical models predict the continued spread of $A e$. aegypti in North America due to a variety of factors including human population expansion, mosquito spread to densely populated urban areas, and theoretically climate change [65].

Ae. aegypti and to a lesser extent Aedes albopictus are thought to be primarily responsible for the resurgence of dengue and introduction of Zika and Chikungunya in the USA [64••]. Most cases of these diseases are travel related, but autochthonous (local) transmission of all three viruses has been reported [64••]. The continued spread of these diseases will depend on mosquito control and social lifestyle changes.

WNV and other zoonotically transmitted mosquito-borne viruses raise more concern for widespread outbreaks, as it is all but impossible to eliminate the animal host. Since its appearance in New York State in 1999, WNV has spread throughout the continental USA and southern Canada [64••].

The epidemiology, clinical presentation, diagnosis, and treatment of each of the major mosquito-borne illnesses currently found in the USA are provided in the following sections. See Table 1 for information on mosquito-borne illness prevention.

\section{West Nile Virus}

\section{Epidemiology}

WNV is the most common mosquito-borne illness in the USA. WNV was a known cause of febrile illnesses in parts of Africa, Asia, and Europe between 1937 and 1998. However, the first case in the Western Hemisphere was not reported until 1999 in New York. Since then, the virus has spread to every state in the continental USA and Alaska with continually increasing numbers [66]. In 2018, 2544 cases were reported, with the highest incidences in Nebraska, California, North Dakota, and Illinois [66]. Human cases occur most frequently during the summer and fall months.

WNV is a small, enveloped virus within the Flaviviridae family that is typically transmitted via infected mosquitos who acquire the virus by feeding on birds. Culex mosquitos are the primary vector, but other mosquito species are also implicated [67]. Transmission has been known to occur through blood transfusion, donated organs, during pregnancy, and breast feeding [67, 68•].

\section{Clinical Presentation}

Although most WNV cases are asymptomatic, approximately $20 \%$ of those infected develop a febrile illness and less than $1 \%$ develop serious illness [68•]. WNV should be considered in anyone with a febrile or acute neurological illness with recent exposure to mosquito or other means of transmission.

Following an incubation period of 2-6 days, WNV infection manifests as fever, headache, weakness, and myalgias/ arthralgias; gastrointestinal symptoms and a maculopapular rash sometimes occur as well. Neuroinvasive disease may manifest as meningitis, encephalitis, or acute flaccid paralysis. WNV meningitis presents similarly to other types of aseptic meningitis. However, WNV encephalitis is a more severe disease with AMS, seizures, and focal neurological deficits. Acute flaccid paralysis resembling polio may occur and progress to respiratory paralysis. Older and immunocompromised patients are more likely to develop severe disease [68•, 69]. Most patients recover completely, but those with more severe disease may have persistent neurological deficits. Among patients with neuroinvasive disease, the overall mortality rate is $10 \%$, with higher death rates in cases of encephalitis or flaccid paralysis [68•]. 


\section{Diagnosis and Treatment}

Routine laboratory testing is generally not helpful in diagnosing WNV. In neuroinvasive disease, CSF analysis exhibits a lymphocytic pleocytosis, though neutrophils may predominate early on. Definitive testing is accomplished through studies of blood or serum for WNV-specific IgM. There is some incidence of cross-reaction with other viruses, and confirmatory testing with neutralizing antibody testing comparing acute and convalescent specimens should be performed [69].

Treatment of WNV is generally supportive for mild disease. There is no proven treatment for neuroinvasive disease. Small studies have looked at treatment of WNV and other flaviviruses with immunoglobulins, interferon, ribavirin, and corticosteroids; however, none of these treatments have shown to be clearly beneficial [70]. In addition, there are no vaccines available against WNV or other flaviviruses though several vaccines are under development [71].

Prevention of WNV is accomplished through local mosquito control programs and personal protective measures. Healthcare providers should remind patients to use mosquito repellants, wear long sleeve shirts and long pants, and limit being outdoors from dusk to dawn to help prevent mosquitoborne illnesses. Mosquito repellants with known efficacy against WNV vectors include DEET, Picardin, and Oil of Lemon Eucalyptus (https://wwwnc.cdc.gov/travel/ yellowbook/2018/the-pre-travel-consultation/protectionagainst-mosquitoes-ticks-other-arthropods) (see Table 2).

\section{Zika}

\section{Epidemiology}

Zika is an arbovirus of the Flaviviridae family. It is related to dengue and was first documented in Africa in 1947 [72••]. It is associated with severe congenital neurologic abnormalities including microcephaly, brain malformation, eye anomalies, neural tube defects, arthrogryposis, and congenital deafness [73]. While previously endemic to only Southeast Asia, there have been several recent outbreaks in the Dominican Republic, Brazil, and Miami since March 2015 when several Brazilian infants were born with microcephaly [72••, 74, 75]. Zika was declared a WHO global public health emergency in 2016 [72••]. Humans and non-human primates serve as the reservoir, with humans living in densely populated urban centers most relevant to disease prevalence in North America [72••].

The natural vector in North America is the Ae. aegypti mosquito, although other mosquito species have been identified as less efficient carriers [72••, 76]. In addition to vertical transmission and mosquito-borne infection, sexual transmission, blood exposure, and laboratory transmission have been reported [77]. Current WHO recommendations advise abstinence from sexual activity for 6 months for men and 2 months for women returning from areas of active outbreak [78]. The incubation period is 3-14 days, so non-mosquito-borne transmission or alternative diagnoses must be considered in patients presenting outside this window [79].

\section{Clinical Presentation}

The typical clinical presentation involves two or more of the following: rash, joint pain, fever, and conjunctivitis within $3-$ 4 days following exposure $[72 \bullet \bullet, 80,81]$. Severe sequelae are rare but include severe thrombocytopenia, Guillain-Barre, and Dengue-like hemorrhagic shock syndrome [77, 81-85]. These cases have typically been in immunocompromised individuals including pregnant patients and older adults with multiple comorbidities. Most infections are subclinical with an estimated incidence of $9.1 \%$ in healthy children living in endemic regions [75]. The actual incidence in the west is likely underestimated [80].

The risks of Zika infection to the developing fetus persist well past organogenesis with serious complications arising at all stages of pregnancy [73]. Postmortem pathologic analysis of fetal tissue demonstrates viral replication in both placental and fetal brain tissue [86]. However, a longitudinal study of 107 French Polynesian children during early childhood did not demonstrate increased incidence of developmental delay if obvious neurodevelopmental defects were absent at birth [87]. While found in the breast milk of infected mothers for up to 33 days, limited data has not demonstrated transmission to breastfeeding infants. Current recommendations do not discourage breastfeeding although this may change in the future [88].

\section{Diagnosis and Treatment}

Several nucleic acids and immunopeptide-based commercial assays are available although none have been identified as superior [89]. Active virus or viral RNA have been detected in blood samples for up to 81 days and in mosquito isolates for up to 30 days. Storage of whole blood prolongs detection window [90, 91]. IgM has been detected up to 19 months in those exposed $[92,93]$. It has also been detected in semen, vaginal fluid, and breast milk [88, 90, 94]. Given the inherent limitations of passive surveillance and the lack of a reliable screening assay, it may be more practical to monitor spikes in incidence of Zika-related sequela to guide further investigation [85].

The treatment of Zika is supportive and symptom specific. Zika is susceptible to classic disinfectants present in the emergency department and is inactivated by UV radiation. Healthcare workers are protected with standard handwashing and barrier precautions [95]. Since the initial outbreaks in the West, there has been significant investigation of the molecular biology of Zika, and while a commercial vaccine does not yet 
exist, several recent studies in animal models appear promising [96, 97]. The global impact of arboreal disease continues to increase $[72 \bullet \bullet, 98]$. Until such time that successful vaccination protocols have limited the impact of Zika, it will be important for emergency providers to understand the signs, symptoms, and risk factors to appropriately guide disposition and counsel patients presenting with concern for Zika.

\section{Dengue}

\section{Epidemiology}

Dengue virus (DENV) is a single-stranded RNA virus and member of the Flaviviridae family [99, 100•]. Dengue fever is the most prevalent arboviral disease globally with incidences continuing to trend up [99, 100•]. Like Chikungunya and Zika viruses, the primary DENV vector of concern is the Ae. aegypti mosquito [99, 100•]. The year to date number of cases in the continental USA as of May 1, 2019 is 82, all of them being travel associated [101]. However, since 2010, multiple local outbreaks have occurred in southern Texas and southern Florida, as well as in US territories including American Samoa, US Virgin Islands, and Puerto Rico [101].

\section{Clinical Presentation}

During the 3-10-day incubation period, the virus replicates in cutaneous immune cells, then spreads to regional lymph nodes where subsequent replication leads to viremia [99]. Clinical presentation ranges from subclinical disease to dengue hemorrhagic shock syndrome (DSS) [99]. Dengue infection typically occurs in three phases: febrile, critical, and convalescent. The febrile phase lasts 2-7 days and may include headache, myalgias/arthralgias, and mild hemorrhagic symptoms (petechiae, ecchymosis, purpura, epistaxis) [101]. Some dengue patients develop Herman's rash, a diffuse erythematous rash with circular blanched foci, which is considered pathognomonic for the disease [99]. During the critical phase (24$48 \mathrm{~h}$ ), patient's defervesce and plasma leakage occur resulting in effusions, ascites, and hemoconcentration [101]. Most patients will progress to the convalescent phase when the extravasated fluid is resorbed and hemodynamics stabilize.

One in 10 patients progresses to severe dengue or DSS near the onset of the critical phase. DSS is the result of a sudden increase in systemic vascular permeability, leading to rapid extravasation of plasma and hypovolemic shock [99, 100•]. It is crucial to recognize the warning signs of progressionvomiting, severe abdominal pain, pulmonary edema, hepatomegaly, and increasing hematocrit — as aggressive supportive care significantly reduces mortality with DSS [99, 101]. A highly concerning feature of DENV is the substantial increase in the likelihood of severe symptoms in subsequent infections
[99]. Approximately $95 \%$ of all dengue patients requiring inpatient treatment have had prior infections [101].

\section{Diagnosis and Treatment}

Routine laboratory derangements include leukopenia, thrombocytopenia, and mild transaminitis [99]. Definitive diagnosis may be made with PCR or any number of immunoassays recognized by the CDC [101].

Treatment of dengue is entirely supportive. Mild cases may be treated with oral hydration and acetaminophen. Aspirin and non-steroidal anti-inflammatory medications should be avoided due to their antiplatelet effects. Patients with severe dengue should be admitted to an intensive care setting. IV fluids and respiratory support may be required. Prophylactic platelet infusions and corticosteroids have not been demonstrated to be useful [101].

There is a vaccine available for patients age 9-45 worldwide. The WHO recommends routine vaccination only for only those patients with confirmed prior dengue infection as people who have not been previously infected seem to be at risk for severe dengue if infected after being vaccinated [101]. The US Food and Drug administration recently approved a vaccine for use in patients age 9-16 who have laboratoryconfirmed previous dengue infection and live in endemic areas [102]. As with other arboviruses, comprehensive prevention at the population level must focus on vector control strategies (see Table 1).

\section{Chikungunya}

\section{Epidemiology}

Chikungunya virus (CHKV) is a single-stranded, positivesense RNA virus of the Togaviridae family [103]. It was first characterized in 1952 in Tanzania and has since become endemic in Africa and Southeast Asia [103, 104]. CHKV drew public attention in the Western hemisphere after emerging in 2013 in St. Martin [104, 105]. In 2014, approximately one million cases were reported in the Western Hemisphere, including 2811 in the USA, 12 of which were locally transmitted [106]. Like other arboviruses (dengue and Zika), the primary vector in North America is the Ae. aegypti mosquito [103, 107, 108]. Mathematical models of the effect of climate change on Ae. aegypti distribution in North America indicate the incidence of chikungunya may continue to increase [108].

\section{Clinical Presentation}

After an incubation period of 1-7 days, the virus disseminates to the skin, muscle, and connective tissue accounting for the classic presentation of fever, symmetric incapacitating polyarticular arthralgias, and diffuse maculopapular rash 
[104]. Clinical presentation ranges from subclinical to incapacitating disease. CHKV is perhaps best known for causing severe polyarthralgias, which typically resolve within 3 weeks but can linger for months to years and eventually result in severe disability [104, 107].

Uncommon sequela includes myelitis, retinitis, meningoencephalitis, conjunctivitis, epistaxis, and subconjunctival hemorrhage [104, 107]. Cardiac complications include arrhythmias, murmurs, myocarditis, and cardiomyopathy [109••]. Compared to adults, children are less likely to have arthralgias and data is conflicting regarding predilection for neurologic sequela $[106,107]$. Older adults are at risk for the more severe cardiac and neuro-inflammatory complications [107]. Vertical transmission occurs but infants with CHKV infection generally have uncomplicated mild infections resolving by the second week of life [107].

\section{Diagnosis and Treatment}

Laboratory studies generally reveal non-specific findings including elevation in inflammatory markers and blood counts. Definitive diagnosis can only be made by immunologic or nucleic acid studies [103]. Imaging is useful to exclude other etiologies of joint pain and neurologic symptoms. Echocardiography is non-diagnostic but may assist in evaluating cardiac manifestations.

Treatment of chikungunya is primarily supportive; patients with persistent arthropathy may benefit from NSAIDs and/or physical therapy [103]. No vaccine currently exists but recent murine models have produced encouraging results $[103,110]$. Until effective vaccines are available, experts agree that control of CHKV and emerging arboviruses is reliant upon preventive measures including robust surveillance and mosquito control programs [103, 111•]. See Table 1 for mosquito control strategies.

\section{Conclusion}

The ticks are on the march and the mosquitos are coming! Even with significant intervention, it is likely that the incidence of known vector-borne diseases will continue to increase, and novel diseases will continue to emerge. In addition, current weather trends suggest that many communities are at risk for breakdowns in the systems which prevent the local transmission of viruses like Zika, dengue, and chikungunya. As clinicians, what is our role going forward in preventing, identifying, and treating vector-borne borne diseases?

First, clinicians must educate patients in both the techniques and the importance of tick and mosquito bite avoidance. Many healthcare providers were trained when mosquito bites were mostly an inconvenience, but this is no longer the case. We must teach the dangers of bug bites, just as we teach the dangers of tobacco and alcohol.

Second, clinicians must increasingly consider vector-borne diseases in the differential diagnosis for patients with rashes and febrile illnesses. While these diseases must particularly be considered during warm weather months, any history of travel to endemic areas must also be included. Early treatment of Lyme, RMSF, and other tick-borne diseases is critical to reduction in morbidity and mortality. Making the diagnosis first requires its consideration in the differential. Considering vector-borne diseases may also assist in identification of new and emerging diseases.

Third, clinicians can be advocates at the local, state, and national level for vector-borne disease prevention programs. Public funding and commitment will be required to meet the increasing threat from vector-borne diseases.

\section{Compliance with Ethical Standards}

Conflict of Interest Sandra Lee Werner, Bhanu Kirthi Banda, Christopher Lee Burnsides, and Alexander James Stuber declare no conflict of interest.

Human and Animal Rights and Informed Consent This article does not contain any studies with human or animal subjects performed by any of the authors.

\section{References}

Papers of particular interest, published recently, have been highlighted as:

- Of importance

• Of major importance

1. World Health Organization. Vector-borne diseases fact sheet, February 2017. https://www.who.int/news-room/fact-sheets/ detail/vector-borne-diseases. Accessed 10 May 2019.

2.• Rosenberg R, Lindsey NP, Fischer M, et al. Vital signs: trends in reported vectorborne disease cases - United States and territories, 2004-2016. MMWR Morb Mortal Wkly Rep. 2018;67:496-501. https://doi.org/10.15585/mmwr.mm6717e An excellent visual and statistical summary of the large changes in the prevalence of these diseases over 12 years.

3. Centers for Disease Control and Prevention. Selected tickborne diseases reported to the CDC, U.S., 2016. https://www.cdc.gov/ ticks/tickbornediseases/overview.html

4. Kuehn BM. Tick bite linked to red meat allergy. JAMA. 2018;319(4):332. https://doi.org/10.1001/jama.2017.20802.

5. Cdc.gov. (2017). Lyme disease | Lyme disease | CDC. [online] Available at: https://www.cdc.gov/Lyme/why-is-cdc-concernedabout-Lyme-disease.html. Accessed 23 Apr 2019.

6. Domachowske J. Introduction to clinical infectious diseases: a problem-based approach. 1st ed: Springer International Publishing; 2019.

7.• Beard C, Eisen R, Barker C, Garofalo J, Hahn M, Hayden M et al. The impacts of climate change on human health in the United States: a scientific assessment. Health2016.globalchange.gov. 
2016 [cited 23 April 2019]. Available from: https:/health2016. globalchange.gov/vectorborne-diseases\#. Great summary of current and expected impacts of climate change on health in the coming years.

8. Dumic I, Severnini E. "Ticking bomb": the impact of climate change on the incidence of Lyme disease. Can J Infect Dis Med Microbiol. 2018 [cited 23 April 2019]; 2018:1-10. Available from: https://www.hindawi.com/journals/cjidmm/2018/5719081/.

9. Hu L. Lyme disease symptoms and diagnosis (beyond the basics). Uptodate.com. 2018 [cited 23 April 2019]. Available from: https:// www.uptodate.com/contents/Lyme-disease-symptoms-anddiagnosis-beyond-the-basics.

10. Diagnosis and testing | Lyme disease $\mid$ CDC [Internet]. Cdc.gov. 2018 [cited 23 April 2019]. Available from: https://www.cdc.gov/ Lyme/diagnosistesting/labtest/otherlab/index.html.

11. Dessau R, van Dam A, Fingerle V, Gray J, Hovius J, Hunfeld K et al. To test or not to test? Laboratory support for the diagnosis of Lyme borreliosis: a position paper of ESGBOR, the ESCMID study group for Lyme borreliosis. European Society of Clinical Microbiology and Infectious Diseases [Internet]. 2018 [cited 23 April 2019];24(2): Pages 118-124. Available from: https://www. clinicalmicrobiologyandinfection.com/article/S1198-743X(17) 30488-3/fulltext\#sec2.3.

12. Leeflang M, Ang C, Berkhout J, Bijlmer H, Van Bortel W, Brandenburg A et al. The diagnostic accuracy of serological tests for Lyme borreliosis in Europe: a systematic review and metaanalysis. BMC Infectious Diseases. 2016 [cited 23 April 2019];16(1). Available from: https://bmcinfectdis.biomedcentral. com/articles/10.1186/s12879-016-1468-4.

13. CDC. Babesiosis. Cdc.gov. 2018 [cited 23 April 2019]. Available from: https://www.cdc.gov/parasites/babesiosis/gen info/index. html.

14. Diuk-Wasser M, Vannier E, Krause P. Coinfection by the tickborne pathogens Babesia microti and Borrelia burgdorferi: ecological, epidemiological and clinical consequences. Trends Parasitol. 2017 [cited 23 April 2019];32(1):30-42. Available from: https://www.ncbi.nlm.nih.gov/pmc/articles/PMC4713283/. Highlights the need to consider and potentially treat for more than one tick-borne disease - especially in patients who are sicker than expected.

15. Radolf J, Caimono M, Stevenson B, Hu L. Of ticks, mice and men: understanding the dual-host lifestyle of Lyme disease spirochaetes. Nat Rev Microbiol. 2012 [cited 23 April 2019];10(2):8799. Available from: https://www.ncbi.nlm.nih.gov/pmc/articles/ PMC3313462/.

16. Ward S, Stramer S, Szczepiorkowski Z. Assessing the risk of Babesia to the United States blood supply using a risk-based decision-making approach: report of AABB's Ad Hoc Babesia Policy Working Group (original report). Transfusion. 2018 [cited 23 April 2019];58(8):1916-1923. Available from: https:// onlinelibrary.wiley.com/doi/full/10.1111/trf.14912.

17. Zimmer A, Simonsen K. Babesiosis. Ncbi.nlm.nih.gov. 2018 [cited 23 April 2019]. Available from: https://www.ncbi.nlm.nih. gov/books/NBK430715/

18. Herwaldt B, McGovern P, Gerwel M, Easton R, MacGregor R. Endemic babesiosis in another eastern state: New Jersey. Emerg Infect Dis. 2003 [cited 23 April 2019];9(2):184-188. Available from: https://www.ncbi.nlm.nih.gov/pmc/articles/PMC2901950/.

19. Alvarez De Leon S, Srivastava P, Revelo A, Kadambi A, El Khoury $\mathrm{M}$, Wormser $\mathrm{G}$, et al. Babesiosis as a cause of acute respiratory distress syndrome: a series of eight cases. Postgraduate Medicine. 2018 [cited 23 April 2019];131(2):138-143. Available from: https://www. tandfonline.com/doi/abs/10.1080/00325481.2019.1558910.

20. Patel K, Johnson J, Reece R, Mermel L. Babesiosis-associated splenic rupture: case series from a hyperendemic region. Clin Infect Dis. 2018.
21. Fida M, Hamdi A, Saleh O, O’HJ. Babesiosis: retrospective review of 38 cases from Upper Midwest. Open Forum Infect Dis. 2018;5(1).

22. Epidemiology and statistics | Rocky Mountain spotted fever (RMSF) | CDC [Internet]. Cdc.gov. 2019 [cited 23 April 2019]. Available from: https://www.cdc.gov/rmsf/stats/index.html.

23. Biggs H, Barton Behravesh C, Bradley K, Dahlgren F, Drexler N, Dumler J, et al. Diagnosis and management of tickborne rickettsial diseases: Rocky Mountain spotted fever and other spotted fever group rickettsioses, ehrlichioses, and anaplasmosis-United States. Morb Mortal Wkly Rep. 2016 [cited 26 April 2019];65(2). Available from: https://www.cdc.gov/mmwr/ volumes/65/rr/pdfs/rr6502.pdf.

24. For public health officials | Rocky Mountain spotted fever (RMSF) | CDC [Internet]. Cdc.gov. 2019 [cited 23 April 2019]. Available from: https://www.cdc.gov/rmsf/info/index.html.

25. Masters E, Olson G, Weiner S. Rocky Mountain spotted fever a clinician's dilemma. Arch Intern Med. 2003 [cited 23 April 2019];163(7):769-774. Available from: https://jamanetwork. com/journals/jamainternalmedicine/fullarticle/215364.

26. Clinical and laboratory diagnosis $\mid$ Rocky Mountain spotted fever (RMSF) | CDC. Cdc.gov. 2018 [cited 23 April 2019]. Available from: https://www.cdc.gov/rmsf/healthcare-providers/ClinLabDiagnosis.html.

27. Risk factors for fatal outcome from Rocky Mountain spotted fever in a highly endemic area-Arizona, 2002-2011. Clin Infect Dis. 2015 [cited 23 April 2019];60(11):1659-66. Available from: https://www.ncbi.nlm.nih.gov/pubmed/25697742.

28. Cross R, Ling C, Day NP, et al. Revisiting doxycycline in pregnancy and early childhood - time to rebuild its reputation? Expert Opin Drug Saf. 2016;15:367-82.

29. Sexton D, McClain M. UpToDate [Internet]. Uptodate.com. 2017 [cited 23 April 2019]. Available from: https://www.uptodate.com/ contents/treatment-of-rocky-mountain-spotted-fever?search= rmsf\%20doxycyline\&source $=$ search_result\&selectedTitle $=$ 1 150\&usage_type=default\&display_rank=1\#H4101120159 \.

30. Zientek J, Dahlgren F, McQuiston J, Regan J. Self-reported treatment practices by healthcare providers could lead to death from Rocky Mountain spotted fever. J Pediatr. 2014 [cited 23 April 2019];164(2):416-418. Available from: https://www.jpeds.com/ article/S0022-3476(13)01236-5/fulltext. Demonstrates consequences of providers clinging to outdated information and dogma rather than evidence.

31. Barton Behravesh C, Schutze G. Doxycycline can be used in young children without staining teeth. AAP News. 2015 [cited 23 April 2019];36(5). Available from: https://www. aappublications.org/content $/ 36 / 5 / 16$ ?sso $=1 \&$ sso redirect count $=$ $1 \&$ nfstatus $=401 \&$ nftoken $=00000000-0000-0000-0000$ $000000000000 \&$ nfstatusdescription=ERROR\%3a+No+local+ token.

32. Todd S, Dahlgren F, Traeger M, Beltrán-Aguilar E, Marianos D, Hamilton C, et al. No visible dental staining in children treated with doxycycline for suspected Rocky Mountain spotted fever. J Pediatr. 2015 [cited 23 April 2019];166(5):1246-1251. Available from: https://www.jpeds.com/article/S0022-3476(15)00135-3/ fulltext.

33. Sexton DJ, McClain MT (2018) Human ehrlichiosis and anaplasmosis. In: UpToDate. https://www.uptodate.com/contents/humanehrlichiosis-and-anaplasmosis? $\mathrm{search}=$ ehrlichiosis $\&$ source $=$ search_result\&selected Title $=1 \sim 50 \&$ usage_ty pe $=$ default\&display rank=1. Accessed 7 May 2019 Topic last updated: Aug, 302018.

34. Nichols Heitman K, Dahlgren FS, Drexler NA, et al. Increasing incidence of ehrlichiosis in the United States: a summary of national surveillance of Ehrlichia chaffeensis and Ehrlichia ewingii 
infections in the United States, 2008-2012. Am J Trop Med Hyg. 2016;94:52-60.

35. Centers for Disease Control and Prevention. Diagnosis and management of tickborne rickettsial diseases: Rocky Mountain spotted fever rickettsioses, ehrlichiosis, and anaplasmosis - United States: a practical guide for healthcare and public health professionals. MMWR. 2016;65(No. RR-2). Accessed 16 May 2019.

36. Engel J, Bradley K, et al. Revision of the national surveillance case definition for ehrlichiosis (ehrlichiosis/anaplasmosis). Council of State and Territorial Epidemiologists, Infectious Diseases Committee, 2007 Position Statement. http://c.ymcdn.com/sites/ www.cste.org/resource/resmgr/PS/07-ID-03.pd.

37. Bakken JS, Dumler JS. Human granulocytic anaplasmosis. Infect Dis Clin N Am. 2015;29:341-55.

38. Centers for Disease Control. Anaplasmosis. Available at https:// www.cdc.gov/anaplasmosis/index.html.

39. Diagnosis and management of tickborne rickettsial diseases: Rocky Mountain spotted fever and other spotted fever group rickettsioses, ehrlichioses, and anaplasmosis-United States: a practical guide for health care and public health professionals. 2016. Cdc-pdf [PDF - 48 pages].

40. Barbour AG. Microbiology, pathogenesis, and epidemiology of relapsing fever. In: UpToDate. 2018. https://www.uptodate.com/ contents/microbiology-pathogenesis-and-epidemiology-ofrelapsing-fever?search=relapsingfever\&source $=$ search result\&selectedTitle $=2 \sim 41$ \&usage_type=default\&display_rank= 2. Accessed 7 May 2019.

41. Centers for Disease Control and Prevention. Tickborne relapsing fever-United States, 1990-2011. MMWR Morb Mortal Wkly Rep. 2015;64(03):58-60.

42. Jones JM, Schumacher M, Peoples M, Souders M, et al. Notes from the field: tickborne relapsing fever outbreak at an outdoor education camp-Arizona, 2014. MMWR Wkly. 2015;64(23): $651-2$.

43. Dworkin MS, Schwan TG, Anderson DE, et al. Tick-borne relapsing fever. Infect Dis Clin N Am. 2008;22:449-68.

44. Barbour AG. Clinical features, diagnosis, and management of relapsing fever. In: UpToDate. 2018. https://www.uptodate.com/ contents/clinical-features-diagnosis-and-management-ofrelapsing-fever? search=relapsingfever\&source $=$ search result\&selectedTitle $=1 \sim 41 \&$ usage type $=$ default\&display_rank $=$ 1. Accessed 7 May 2019.

45. Centers for Disease Control. Tick-borne relapsing fever. In: CDC. 2018. Available at https://www.cdc.gov/relapsing-fever/clinicians/ index.html. Accessed 7 May 2019.

46. Sexton DJ, McClain MT (2017) Southern tick-associated rash illness (STARI). In: UpToDate. https://www.uptodate.com/ contents/southern-tick-associated-rash-illness-stari?search= stari\&source $=$ search_result\&selectedTitle $=1 \sim 129 \&$ usage_type $=$ default\&display_rank=1. Accessed 7 May 2019 Topic last updated: Jul 24, 2017.

47. Feder HM Jr, Hoss DM, Zemel L, et al. Southern tick-associated rash illness (STARI) in the north: STARI following a tick bite in Long Island, New York. Clin Infect Dis. 2011;53:e142.

48. Wormser GP, Liveris D, Nowakowski J, Nadelman RB, Holmgren D, Bittker S, et al. Microbiologic evaluation of patients from Missouri with erythema migrans. Clin Infect Dis. 2005;40(3): 423-8. https://doi.org/10.1086/427289.

49. Centers for Disease Control. STARI or Lyme? Available at https:// www.cdc.gov/stari/disease/index.html. Updated November 2018. Accessed 15 May 2019.

50. Tularemia. Centers for disease control. https://www.cdc.gov/ tularemia. Accessed 7 May 2019 Topic last updated: Jan 14, 2019.

51. Pedati C, House J, Hancock-Allen J, Colton L, Bryan K, Ortbahn D, et al. Notes from the field: increase in human cases of tularemia-
Colorado, Nebraska, South Dakota, and Wyoming, JanuarySeptember 2015. MMWR Morb Mortal Wkly Rep. 2015;64:1317-8.

52. Nakazawa Y, Williams R, Peterson AT, et al. Climate change effects on plague and tularemia in the United States. Vector Borne Zoonotic Dis. 2007;7:529 Good discussion of effects of warming climate on potentially serious diseases.

53. Matyas BT, Nieder HS, Telford SR 3rd. Pneumonic tularemia on Martha's Vineyard: clinical, epidemiologic, and ecological characteristics. Ann N Y Acad Sci. 2007;1105:351-77.

54. Dennis DT, Inglesby TV, Henderson DA, Bartlett JG, Ascher MS, Eitzen E, et al. Tularemia as a biological weapon: medical and public health management. JAMA. 2001;285:2763.

55. Penn RL. Tularemia: clinical manifestations, diagnosis, treatment, and prevention. In: UpToDate. 2019. https://www.uptodate.com/ contents/clinical-manifestations-diagnosis-and-treatment-oftularemia. Accessed 7 May 2019. Topic last updated: Jan 14, 2019.

56.• Fatmi SS, Zehra R, Carpenter DO. Powassan virus-a new reemerging tick-borne disease. Front Publ Health. 2017;5:342. https://doi.org/10.3389/fpubh.2017.00342 A re-emergent disease that must be considered in the differential of tick-borne diseases.

57. Centers for Disease Control. Powassan virus. Available at https:// www.cdc.gov/powassan/index.html Updated December 4, 2018. Accessed 16 May 2019.

58. Frost HM, Schotthoefer AM, Thomm AM, Dupuis AP, Kehl SC, Kramer L, et al. Serologic evidence of Powassan virus infection in patients with suspected Lyme disease. Emerg Infect Dis. 2017;23(8):1384-8. https://doi.org/10.3201/eid2308.16197.

59. Centers for Disease Control. Heartland virus. Available at https:// www.cdc.gov/heartland-virus/index.html Updated October 22, 2018. Accessed 10 May 2019. An emerging pathogen with potential fatal outcomes.

60. Centers for Disease Control. Bourbon virus. Available at https:// www.cdc.gov/ncezid/dvbd/bourbon/index.html Updated January 24, 2019. Accessed 10 May 2019. An emerging pathogen with potential fatal outcomes.

61. Savage HM, Godsey MS, Panella NA, et al. Surveillance for heartland virus (Bunyaviridae: Phlebovirus) in Missouri during 2014: first detection of virus in adults of Amblyomma americanum (Acari: Ioxodidae). J Med Entomol. 2016;53(3): 607-12.

62. Kosoy OI, Lambert AJ, Hawkinson DJ, Pastula DM, Goldsmith CS, Hunt DC, et al. Novel Thogotovirus species associated with febrile illness and death, United States, 2014. Emerg Infect Dis. 2015;21(5):760-4.

63. Muehlenbachs A, Fata CR, Lambert AJ, Paddock CD, Velez JO, Blau DM, et al. Heartland virus associated death in Tennessee. Clin Infect Dis. 2014;59(6):845-50.

64.• Moreno MJ, Turell M. History of mosquito-borne diseases in the United States and implications for new pathogens. Emerg Infec Dis. 2018;24(5):821-5. https://doi.org/10.3201/eid2405:171609 Well researched and sheds light on potential increase in vector-borne pathogens.

65. Kraemer MUG, Reiner RC Jr, Brady OJ, Messing JP, et al. Past and future spread of the arbovirus vectors Aedes aegypti and Aedes albopictus. Nat Microbiol. 2019;4(5):854-63.

66. Center for Disease Control and Prevention. West Nile virus statistics and maps. Available at https://www.cdc.gov/westnile/ statsmaps/index.html.

67. Hayes EB, Komar N, Nasci RS, Montgomery SP, O'Leary DR, Campbell GL. Epidemiology and transmission dynamics of West Nile virus disease. Emerg Infect Dis. 2005;11(8):1167-73. https:// doi.org/10.3201/eid1108.050289a. Accessed 16 May 2019.

68. Yeung MW, Shing E, Nelder M, Sander B. Epidemiologic and clinical parameters of West Nile virus infections in humans: a 
scoping review. BMC Infect Dis. 2017;17(1):609. Published 2017 Sep 6. https://doi.org/10.1186/s12879-017-2637. Accessed 16 May 2019. Comprehensive review of this now widespread pathogen.

69. US Department of Health and Human Services, Public Health Services, Centers for Disease Control, West Nile virus in the United States: guidelines for surveillance, Prev Control. 2013. https://www.cdc.gov/westnile/resources/pdfs/wnvGuidelines.pdf. Accessed 16 May 2019.

70. Centers for Disease Control and Prevention. West Nile virus therapeutics, a review of the literature. February 2018. For health care providers. Available at https://www.cdc.gov/westnile/resources/ pdfs/WNV-therapeutics-summary-P.pdf. Accessed 16 May 2019.

71. Scherwitzl I, Mongkolsapaja J, Screaton G. Recent advances in human flavivirus vaccines. Curr Opin Virol. 2017;23:95-101. https://doi.org/10.1016/j.coviro.2017.04.002.

72.• Petersen L, Jamieson D, Powers A, Honein M. Zika virus. New Engl J Med. 2016;74:1552-63. https://doi.org/10.1056/ NEJMra1602113 Great introduction to this emerging disease.

73. Eggo RM, Kucharski AJ. Expected duration of adverse pregnancy outcomes after zika epidemic. Emerg Infect Dis. 2018;24(1):12730. https://doi.org/10.3201/eid2401.170482.

74. Mutebi J, Hughes HR, Burkhalter KL, et al. Zika virus MB16-23 in mosquitoes, Miami-Dade County, Florida, USA, 2016. Emerg Infect Dis. 2018;24(4):808-10. https://doi.org/10.3201/eid2404. 171919.

75. Sasmono R, Dhenni R, Yohan B, et al. Zika virus seropositivity in 1-4-year-old children, Indonesia, 2014. Emerg Infect Dis. 2018;24(9):1740-3. https://doi.org/10.3201/eid2409.180582.

76. Hart CE, Roundy CM, Azar SR, Huang JH, Yun R, Reynolds E, et al. Zika virus vector competency of mosquitoes, Gulf Coast, United States. Emerg Infect Dis. 2017;23(3):559-60. https://doi. org/10.3201/eid2303.161636.

77. Krow-Lucal ER, Novosad SA, Dunn AC, Brent CR, Savage HM, Faraji A, et al. Zika virus infection in patient with no known risk factors, Utah, USA, 2016. Emerg Infect Dis. 2017;23(8):1260-7. https://doi.org/10.3201/eid2308.170479.

78. World Health Organization. Zika virus fact sheet. https://www. who.int/news-room/fact-sheets/detail/zika-virus. Accessed 30 March 2019.

79. Krow-Lucal ER, Biggerstaff BJ, Staples J. Estimated incubation period for Zika virus disease. Emerg Infect Dis. 2017;23(5):8415. https://doi.org/10.3201/eid2305.161715.

80. Wahnich A, Clark S, Bloch D, Kubinson H, Hrusa G, Liu D, et al. Surveillance for mosquito borne transmission of Zika virus, New York City, NY, USA, 2016. Emerg Infect Dis. 2018;24(5):827-34. https://doi.org/10.3201/eid2405.170764.

81. Peña F, Pimentel R, Khosla S, Mehta SD, Brito MO. Zika virus epidemic in pregnant women, Dominican Republic, 2016-2017. Emerg Infect Dis. 2019;25(2):247-55. https://doi.org/10.3201/ eid2502.181054.

82. Boyer Chammard T, Schepers K, Breurec S, Messiaen T, Destrem $\mathrm{AL}$, Mahevas M, et al. Severe thrombocytopenia after Zika virus infection, Guadeloupe, 2016. Emerg Infect Dis. 2017;23(4):6968. https://doi.org/10.3201/eid2304.161967.

83. Howard A, Visintine J, Fergie J, Deleon M. Two infants with presumed congenital Zika syndrome, Brownsville, Texas, USA, 2016-2017. Emerg Infect Dis. 2018;24(4):625-30. https://doi. org/10.3201/eid2404.171545.

84. Sousa AQ, Cavalcante D, Franco LM, et al. Postmortem findings for 7 neonates with congenital Zika virus infection. Emerg Infect Dis. 2017;23(7):1164-7. https://doi.org/10.3201/eid2307.162019.

85. Barcellos C, Xavier D, Pavão A, et al. Increased hospitalizations for neuropathies as indicators of Zika virus infection, according to health information system data, Brazil. Emerg Infect Dis. 2016;22(11):1894-9. https://doi.org/10.3201/eid2211.160901.
86. Bhatnagar J, Rabeneck DB, Martines RB, Reagan-Steiner S, Ermias Y, Estetter LBC, et al. Zika virus RNA replication and persistence in brain and placental tissue. Emerg Infect Dis. 2017;23(3):405-14. https://doi.org/10.3201/eid2303.161499.

87. Subissi L, Dub T, Besnard M, Mariteragi-Helle T, Nhan T, Lutringer-Magnin D, et al. Zika virus infection during pregnancy and effects on early childhood development, French Polynesia, 2013-2016. Emerg Infect Dis. 2018;24(10):1850-8. https://doi. org/10.3201/eid2410.172079.

88. Sotelo JR, Sotelo AB, Sotelo F, et al. Persistence of Zika virus in breast milk after infection in late stage of pregnancy. Emerg Infect Dis. 2017;23(5):854-6. https://doi.org/10.3201/eid2305.161538.

89. Safronetz D, Sloan A, Stein DR, Mendoza E, Barairo N, Ranadheera C, et al. Evaluation of 5 commercially available Zika virus immunoassays. Emerg Infect Dis. 2017;23(9):157780. https://doi.org/10.3201/eid2309.162043.

90. Murray KO, Gorchakov R, Carlson AR, Berry R, Lai L, Natrajan $\mathrm{M}$, et al. Prolonged detection of Zika virus in vaginal secretions and whole blood. Emerg Infect Dis. 2017;23(1):99-101. https:// doi.org/10.3201/eid2301.161394.

91. Burkhalter KL, Savage HM. Detection of Zika virus in desiccated mosquitoes by real-time reverse transcription PCR and plaque assay. Emerg Infect Dis. 2017;23(4):680-1. https://doi.org/10. 3201/eid2304.161772.

92. Griffin I, Martin SW, Fischer M, Chambers TV, Kosoy O, Falise A, et al. Zika virus IgM detection and neutralizing antibody profiles 12-19 months after illness onset. Emerg Infect Dis. 2019;25(2):299-303. https://doi.org/10.3201/eid2502.181286.

93. Mansuy J, Mengelle C, Pasquier C, et al. Zika virus infection and prolonged viremia in whole-blood specimens. Emerg Infect Dis. 2017;23(5):863-5. https://doi.org/10.3201/eid2305.161631.

94. Harrower J, Kiedrzynski T, Baker S, Upton A, Rahnama F, Sherwood J, et al. Sexual transmission of Zika virus and persistence in semen, New Zealand, 2016. Emerg Infect Dis. 2016;22(10):1855-7. https://doi.org/10.3201/eid2210.160951.

95. Müller JA, Harms M, Schubert A, Jansen S, Michel D, Mertens T, et al. Inactivation and environmental stability of Zika virus. Emerg Infect Dis. 2016;22(9):1685-7. https://doi.org/10.3201/eid2209. 160664 .

96. Nürnberger C, Bodmer BS, Fiedler AH, Gabriel G, Mühlebach $\mathrm{MD}$. A measles virus-based vaccine candidate mediates protection against Zika virus in an allogeneic mouse pregnancy model. J Virol. 2019;93(3):e01485-18. https://doi.org/10.1128/JVI.0148518.

97. Zhan Y, Deng Y, Huang B, Song Q, Wang W, Yang Y, et al. Humoral and cellular immunity against both ZIKV and poxvirus is elicited by a two-dose regimen using DNA and non-replicating vaccinia virus-based vaccine candidates. Vaccine. 2019;37(15): 2122-30. https://doi.org/10.1016/j.vaccine.2019.02.063.

98. Leta S, Beyene TJ, De Clercq EM, Amenu K, Kraemer MUG, Revie CW. Global risk mapping for major diseases transmitted by Aedes aegypti and Aedes albopictus. Int J Infect Dis. 2018;67:2535. https://doi.org/10.1016/j.ijid.2017.11.026.

99. Waterman SH, Margolis HS, Sejvar JJ. Surveillance for dengue and dengue-associated neurologic syndromes in the United States. Am J Trop Med Hyg. 2015;92(5):996-8. https://doi.org/10.4269/ ajtmh.14-0016.

100. Guarner J, Hale GL. Four human diseases with significant public health impact caused by mosquito-borne flaviviruses: West Nile, Zika, dengue and yellow fever. Semin Diagn Pathol. 2019;36: 170-6. https://doi.org/10.1053/j.semdp.2019.04.009. Excellent intro/review of these emerging diseases.

101. Centers for Disease Control. Dengue. Available at https://www. cdc.gov/dengue/index.html. Updated on May 3, 2019. Accessed 22 May 2019. 
102. Fist FDA-approved vaccine for the prevention of dengue disease in endemic regions. Press release. https://www.fda.gov/newsevents/press-announcements/first-fda-approved-vaccineprevention-dengue-disease-endemic-regions. May 1, 2019.

103. Kendra JA, Advani VM, et al. Functional and structural characterization of the chikungunya virus translational recoding signals. J Biol Chem. 2018;293(45):17536-45. https://doi.org/10.1074/jbc. RA118.005606.

104. Powers, AM, Endy, TP. Ch 36: viral febrile illnesses and emerging pathogens. Hunter's tropical medicine and emerging infectious disease, 10th edn. Canada: Elsevier Inc. 2020. Accessed 5/7/2019.

105. Nasserie T, Brent SE, Tuite AR, Moineddin R, Yong JHE, Miniota $\mathrm{J}$, et al. Association between air travel and importation of chikungunya into the United States. J Travel Med. 2019; $10.1093 / \mathrm{jtm} / \mathrm{taz} 028$.

106. Ward CE, Chapman JI. Chikungunya in children: a clinical review. Pediatr Emerg Care. 2018;34(7):510-5. https://doi.org/10.1097/ PEC.0000000000001529.

107. Liu LE, Dehning M, Phipps A, Swienton RE, Harris CA, Klein KR. Clinical update on dengue, chikungunya, and Zika: what we know at the time of article submission. Disaster Med Public Health Prep. 2017 Jun;11(3):290-9. https://doi.org/10.1017/dmp.2016. 144.

108. Alvarez MF, Bolívar-Mejía A, Rodriguez-Morales AJ, RamirezVallejo E. Cardiovascular involvement and manifestations of systemic chikungunya virus infection: a systematic review. F1000Res. 2017;6:390. https://doi.org/10.12688/f1000research. 11078.2.

109.• Kamal M, et al. Mapping the global potential distributions of two arboviral vectors Aedes aegypti and Ae. albopictus under changing climate. PLoS ONE. 2018. https://doi.org/10.1371/journal.pone. 0210122 Scary picture of where the mosquitos are headed.

110. Dora EG, Rossi SL, Weaver SC, Tucker SN, Mateo R. An adjuvanted adenovirus 5-based vaccine elicits neutralizing antibodies and protects mice against chikungunya virus-induced footpad swelling. Vaccine. 2019. https://doi.org/10.1016/j.vaccine. 2019.04.069.

111. Fernandes JN, Moise IK, Maranto GL, Beier JC. Revamping mosquito-borne disease control to tackle future threats. Trends Parasitol. 2018;34(5):359-68. https://doi.org/10.1016/j.pt.2018. 01.005 Motivation for public action to prevent future outbreaks.

Publisher's Note Springer Nature remains neutral with regard to jurisdictional claims in published maps and institutional affiliations. 